\title{
Reliability and Responsiveness of the Korean Version of the Trunk Impairment Scale for Stroke Patients
}

\author{
Jooyeon Ko ${ }^{1}$, Youngyoul You ${ }^{2}$ \\ 'Department of Physical Therapy, Daegu Health College, Daegu; ${ }^{2}$ Rehabilitation Therapy Center, Bronco Memorial Hospital, Hwaseong, Korea
}

Purpose: The purposes of this study were to develop the Korean version of the trunk impairment scale (K-TIS) and to examine reliability and responsiveness of the K-TIS in patients with stroke.

Methods Subjects of the study were 51 stroke patients (mean age: 57.78 years) recruited from two stroke clinics. For the interrater and test-retest reliability, two raters measured the K-TIS two times using video clips with an interval of 2 weeks. For the responsiveness, intensive physical therapy training was provided to all participants 2 times a day for one month or three months depending on the onset of the stroke and the admission rules of the two clinics. Inter-rater reliability and test-retest reliability of the K-TIS three subscales (static sitting balance, dynamic sitting balance, and coordination) scores and total scores were examined using intra-correlation coefficient $\left(I C C_{3,1}\right)$ and Pearson's correlation coefficient (r). To examine responsiveness, the minimally important difference (MID) was calculated with effect size.

Results: Inter-rater reliability of the K-TIS subscales and total scores were all high (ICC3,1 $=0.920-0.983$ and $r=0.924-0.984)$. For the test-retest reliability, $I_{2 C} C_{3,1}=0.805-0.901$ and $r=0.806-0.903$, and the MID for acute and post-acute as well as chronic stroke patients remained in the mean change range.

Conclusion: It is suggested that the K-TIS might be used for clinical and research purposes as a standardized tool for stroke patients. In addition, it can also be useful in establishment of treatment goal(s) and planning treatment program(s) for patients with stroke.

Keywords: Trunk impairment scale (TIS), Reliability, Responsiveness

\section{서 론}

뇌졸중은 뇌혈관의 폐쇄 또는 파열로 인하여 갑자기 국소신경학적 장애 또는 의식장애가 발생하여 24시간 이상 지속되는 임상 증상이 다.' 우리나라는 암에 이에 뇌졸중으로 인한 사망률이 두 번째로 높 지만, 단일 장기 질환으로는 사망원인 1 위로, ${ }^{2}$ 뇌졸중 환자의 $60 \%$ 에 서 심각한 장기적 신체장애를 가져온다. ${ }^{3}$

여러 요인들이 뇌졸중 후 기능회복에 영향을 미치지만, ${ }^{4}$ 많은 전향 적 연구에서 앉은 자세에서 균형조절능력과 선별적 몸통의 움직임을 중요한 예측인자로 보고하였다. ${ }^{5,67}$ 앉은 자세에서 균형조절은 앉기, 앉은 자세에서 일어서기, 앉은 자세에서 일어서서 걷기 등을 비롯하 여 일상생활에 필요한 다양한 기능적 활동의 수행에 반드시 필요하 다. 몸통 근육은 골반과 척추를 안정화시켜 다양한 균형활동에서 팔.다리를 조절된 방식으로 효율적으로 움직일 수 있는 토대를 제공
한다. ${ }^{89}$ 최근의 한 연구에서는 몸통조절능력 회복과 기능적 회복이 이루어지는 시간은 비례한다고 보고하였다. ${ }^{10}$ 그러므로 앉은 자세에 서의 균형과 선택적 몸통조절력의 회복은 뇌졸중 환자의 물리치료 에서 예후에 대한 예측인자뿐 아니라 치료계획과 수행에서도 매우 중요한 의미가 있다.

뇌졸중 환자의 앉은 자세에서 균형조절과 몸통조절능력을 제대로 이해하고 임상치료와 연구에 적용하기 위해서는 국제기능장애분류 (International Classification of Functioning, Disability and Health, ICF) 에 근거한 적합한 평가도구가 필요하다. 즉, 뇌졸중 환자의 평가, 기능 적 문제점 설정, 치료목표 설정, 치료계획 등 임상의사결정을 수행하 고 객관적인 자료를 바탕으로 환자의 상태와 물리치료의 효과에 관 하여 환자 및 보호자와의 인터뷰를 위하여 신뢰도와 민감도를 갖춘 평가도구가 필요하다." 문헌조사에 따르면, 뇌졸중 환자의 몸통조절 능력 평가도구로는 Sitting Balance Scale과 ${ }^{12}$ Trunk Control Test ${ }^{13}$ 가 있 
다. 하지만 이 도구들은 신뢰도가 낮거나 몸통의 질적인 움직임과 근 력을 고려하지 않아 임상과 연구의 목적으로 적합하지 못하다. ${ }^{12,13}$ 이 외에도 뇌졸중 환자의 기능평가에서 몸통활동을 한 요소로 평가하 기도 한다. 예를 들자면, Rivermead Motor Assessment의 '다리와 몸통' 영역에서, ${ }^{14}$ Chedoke-McMaster Stroke Assessment의 '자세조절' 부분에 서 뇌졸중 환자의 몸통조절능력을 일부분 평가한다. ${ }^{15}$

몸통손상척도(Trunk Impairment Scale, TIS)는 뇌졸중 환자의 정적 및 동적 앉은 자세에서의 균형과 몸통 움직임의 협응력을 평가해주 는 신뢰도가 검증된 평가도구로, ${ }^{16} \mathrm{ICF}$ 의 신체구조 및 기능과 활동영 역을 평가한다. ${ }^{17} \mathrm{TIS}$ 는 2004년 개발된 이래 현재 여러 뇌졸중 환자의 기능회복과 치료계획에 관한 연구에서 널리 사용되고 있다.710,18 국내 의 경우, 뇌졸중 환자의 물리치료 임상의사결정의 전 과정에서 기능 회복과 높은 연관성을 갖는 앉은 자세에서의 균형조절과 몸통조절 능력을 평가할 수 있는 표준화된 평가도구가 개발되어 있지 않다. 표 준화된 평가도구란 신뢰도와 민감도가 높은 도구를 말한다. 따라서 본 연구에서는 국내의 TIS에 대한 높은 관심과 임상 및 연구목적으 로의 적용을 위한 유용한 자료를 제공하기 위하여 TIS의 한글화와 신뢰도 조사를 실시하였다를 한글화국판으로 개발하고자 한다. 구 체적인 목적은 다음과 같다. 첫째, 영어로 된 TIS를 한국어번역, 영어 번역, 한국어 재 번역 과정을 거쳐 한글화 시킨다. 둘째, 한글화된 TIS 의 측정자간 그리고 검사-재검사 신뢰도를 확인한다. 셋째, 뇌졸중 발 병 3개월 미만의 급성 및 급성기 이후 환자와 발병 6개월 이상 된 만 성 뇌졸중 환자를 대상으로 집중적인 물리치료 효과를 확인하기 위 해 한글화 된 TIS의 점수변화에 대한 민감도를 확인한다.

\section{연구방법}

\section{1. 연구대상 및 시기}

몸통손상척도의 신뢰도와 집중 물리치료 효과의 민감도를 확인하기 위하여 2014년 1월부터 6월까지 경기도 소재 2개의 기관, 즉 재활병원 에서 치료를 받는 만성뇌졸중 환자 12 명과 일반병원에서 치료를 받 는 급성 및 급성기 이후 뇌졸중 환자 39 명, 총 51 명을 편의표본추출하 였다. 우리나라의 재활병원과 일반병원의 뇌졸중환자 입원기간이 다 른 점을 고려할 때 재활병원의 평균입원기간과 치료기간은 6개월 이 상 일반병원은 평균 2 개월이다. 대상자 선정조건은 TIS 원저자의 기 준에 따라 몸통손상척도의 시작자세인 침대 또는 치료 테이블에 기 대거나 손을 짚지 않고 앉을 수 있는 자, 치료사의 지시를 듣고 이해 할 수 있는 MMSE-K 24점 이상인자, 하지에 정형외과적 질환이 없는 자, 그리고 본 연구의 목적을 듣고 자발적으로 실험에 참여를 동의한 자로 하였다(Table 1).
Table 1. General characteristics of the participant

\begin{tabular}{lcc}
\hline \multicolumn{3}{c}{ Variables and category } \\
\hline Age (year) & $16(31.37)$ & $45.06 \pm 3.13$ \\
$41-50$ & $11(21.57)$ & $53.00 \pm 1.67$ \\
$51-60$ & $16(31.37)$ & $65.69 \pm 2.55$ \\
$61-70$ & $8(15.7)$ & $74.00 \pm 3.30$ \\
$71-80$ & $51(100)$ & $57.78 \pm 12.06$ \\
Total & & \\
Sex & $23(45.10)$ & \\
Male & $28(57.90)$ & \\
Female & & \\
Diagnosis & $27(52.94)$ & \\
Hemorrhage & $24(47.06)$ & \\
Infarction & & \\
Affected side & $24(47.06)$ & \\
Right & $27(52.94)$ & \\
Left & & \\
Duration of onset & $39(76.47)$ & \\
90 days $>$ & $12(23.53)$ & \\
180 days $\leq$ & & \\
\hline
\end{tabular}

Values are No (\%) and Mean \pm SD.

\section{2. 측정도구 및 방법}

\section{1) 몸통손상척도(TIS)}

몸통손상척도는 2004년 처음 소개된 뇌졸중환자의 앉은 자세에서 의 정적 및 동적 균형과 몸통의 선택적 움직임을 평가하는 도구이다. 몸통손상척도는 정적앉기균형, 동적앉기균형, 그리고 협응력 등 3 개 의 하위척도로 구성되어 있다. 정적앉기균형 하위척도에서는 환자가 기대거나 손을 짚지 않고 10 초 동안 앉은 자세를 유지하는지, 검사자 가 비마비측 다리를 마비측 다리 위로 교차시켰을 때 이 자세를 유지 하는지, 환자가 스스로 비마비측 다리를 마비측 다리 위로 교차시켰 을 때 몸통이나 상지에서 보상적 움직임이 나타나는지 등의 3 가지 항 목을 평가하여 각기 0-2점, 0-2점, 0-3점을 부여하여 총 0-7점의 점수범 위를 갖는다. 동적앉기균형 하위척도에서는 상부몸통과 하부몸통의 선별적 외측 굽힘의 정도를 검사하는 10 개의 항목으로 구성되며 각 기 0-1점을 부여하여 총 0-10점이 부여된다. 협응력 하부척도는 상부 몸통과 하부몸통의 선별적 회전능력을 측정하는 4 개의 항목으로 구 성되며 항목에 따라 0-1점 또는 0-2점을 부여하여 총 0-6점이 부여된 다. 몸통손상척도는 3 개 하부척도, 총 17 개 항목, 총점 범위는 $0-23$ 점 이다. 몸통손상척도는 개발 당시 평균연령 63세, 발병기간 21일-78개 월 급성 및 만성 뇌졸중 환자 28 명을 대상으로 2 명의 물리치료사가 신뢰도가 조사에 참여하였으며, 그 결과로 검사자 간 및 검사-재검사 급내상관계수는 ICC $=0.85-0.99$ 그리고 ICC $=0.96-0.99$ 였다. ${ }^{17,19} \mathrm{~K}-\mathrm{TIS}$ 는 Appendix 1에서 확인할수 있다. 


\section{2) TIS 한글화 과정}

몸통손상척도가 소개된 이후 뇌졸중 환자의 기능적 회복을 위한 임 상 및 연구목적으로 널리 사용되고 있으며, 한국판몸통손상척도의 개발을 위하여 연구자는 원저자인 Geert Verheyden로 부터 한국판몸 통손상척도 개발에 대한 승인과 트레이닝 DVD를 통해 제공받았다. 외래어로 된 평가도구의 한국판개발을 위한 기본 절차인 한글번역, 영문으로 재 번역, 원저자와 문화적 및 언어적 차이에 따른 내용 수 정, 그리고 다시 한글번역 과정을 거쳐 한글화된 몸통손상척도를 준 비한 다음 한국판몸통손상척도 개발을 위하여 신뢰도와 민감도 조 사를 실시하였다.

\section{3. 통계분석 및 자료처리}

연구대상자의 일반적 특성은 기술통계량을 이용하여 분석하였다. 한글화된 몸통손상척도의 정규성을 검정한 후 검사자 간 및 검사-재 검사 신뢰도 조사를 위하여 급내상관계수(Intraclass correlation coefficient, $\mathrm{ICC}_{3,1}$ ) 및 피어슨상관계수(Pearson's correlation coefficient, r)를 구하였다. ${ }^{20-23}$ 'ICC $\geq 0.90$ ', 'ICC = 0.75-0.90', 'ICC = 0.50-0.75' ' $\mathrm{ICC}=\leq$ 0.50 '등은 각기 신뢰도가 ‘높음, '양호함', '보통', '좋지 않음을 나타내며, 'r $=0.00-0.25$, ' r $=0.25-0.50$, ' $r=0.50-0.75$, ' $r=0.75$ <' 등은 상관관계 없 음, '약간의 상관관계”, '중간에서 좋은 상관관계', '높은 상관관계'를 나타내는 것으로 해석한다. ${ }^{24}$ 민감도 조사를 위하여 MID와 대응표 본 T검정(paired t-test)를 실시하였다. Minimally important difference (MID)는 effect size를 이용하여 $0.3 \times$ baseline SD, $0.5 \times$ baseline SD로 구 하였다. ${ }^{25}$ 자료의 통계처리는 Window SPSS ver 22.0 (IBM Inc., Armonk, $\mathrm{NY}, \mathrm{USA}$ )를 사용하였고, 모든 통계학적 유의수준 $\alpha=0.05$ 로 설정하 였다.

\section{1) 신뢰도 및 민감도 조사}

한글화된 몸통손상척도의 신뢰도 및 민감도 조사를 위하여 뇌졸중 평가 및 치료경험이 3 년 이상 된 물리치료사 4 명 $(\mathrm{A}, \mathrm{B}, \mathrm{C}, \mathrm{D})$ 을 대상으 로 TIS의 각 항목의 내용에 대한 이론 숙지와 트레이닝 DVD를 이용 한 사전 교육을 실시한 후 실제 측정을 시작하였다. 트레이닝 된 측정
자 중 2 명 $(\mathrm{A}$ 및 $\mathrm{B})$ 는 측정자 간 및 검사-재검사 신뢰도 조사를 위하여 환자마다 2주 간격으로 2 회에 걸쳐 몸통손상척도를 사정하고 그 내 용을 비디오로 레코딩하였다. 민감도 조사를 위하여 만성뇌졸중환 자의 경우 첫 측정을 실시한 시점으로부터 검사-재검사 측정을 모두 마친 후 3 개월 후에 그리고 급성 및 급성기 이후 뇌졸중 환자는 1 개월 이후에 각기 추가로 몸통손상척도를 사정하고 마찬가지로 전 평가 과정을 비디오레코딩하였다. 국내의 사정을 고려하여 만성 뇌졸중 환자의 경우 주로 재활병원에서 6개월 이상의 입원치료를 받고 있으 며 치료에 대한 기능적 변화도 12 주 이상의 기간이 필요하므로 3 개월 간의 치료기간을 설정하였고, 급성 및 급성기 이후는 3 개월 미만의 시기에 해당하므로 일반병원에 주로 입원하는 환자들과 이들의 입원 시기를 고려하여 1 개월로 설정하였다. 대상자들은 각기 입원한 병원 에서 1 일 2 회, 주 5 회에 걸쳐 입원기간 동안 집중적인 운동치료를 받 았다. 다른 2 명의 한글화된 TIS 사정을 훈련 받은 측정자 $(\mathrm{C}$ 및 D)는 준비된 비디오 클립을 보면서 한글화된 TIS의 항목별, 3 개의 하위척 도, 그리고 총점 등에 대하여 점수를 부여하였다. 이때, 측정자 $\mathrm{C}$ 와 $\mathrm{D}$ 는 비디오 클립에 대하여 서로 의견을 나누지 못하게 하고 독립적으 로 점수를 부여하도록 하였다.

\section{결 과}

연구대상자의 일반적 특성은 Table 1 그리고 한국판몸통손상척도의 평균과 표준편차는 Table 2 와 같다. 급성 및 급성기이후 12 명의 환자 들의 평균 발병일은 12 일이었다.

\section{1. 한국판몸통손상척도의 측정자 간 및 검사-재검사 신뢰도}

측정자 $\mathrm{C}$ 와 측정자 $\mathrm{D}$ 간에 2주 간격으로 2 회에 걸쳐 실시된 첫 번째 검사자 간 신뢰도는 $\mathrm{ICC}_{3,1}=0.925-0.951, \mathrm{r}=0.940-1.000$, 두 번째 $\mathrm{ICC}_{3,1}=0.920-1.000, \mathrm{r}=0.924-0.984$ 의 높은 신뢰도를 나타냈다(Table 3). 각 측정자의 검사-재검사 신뢰도는 $\mathrm{ICC}^{3,1}$ 과 $\mathrm{r}$ 값이 $0.848,0.849$ (측 정자 C) 그리고 $0.856,0.856$ (측정자 D)로 나타났다(Table 3).

Table 2. Mean and standard deviation of the K-TIS for reliabilities test

$(N=51)$

\begin{tabular}{|c|c|c|c|c|c|c|c|c|}
\hline \multirow{3}{*}{ TIS } & \multicolumn{4}{|c|}{ Rater A } & \multicolumn{4}{|c|}{ Rater B } \\
\hline & \multicolumn{2}{|c|}{ First } & \multicolumn{2}{|c|}{ Second } & \multicolumn{2}{|c|}{ First } & \multicolumn{2}{|c|}{ Second } \\
\hline & Mean (SD) & Min-Max & Mean (SD) & Min-Max & Mean (SD) & Min-Max & Mean (SD) & Min-Max \\
\hline SSB total & $5.8(1.5)$ & $0-7$ & $5.7(1.7)$ & $0-7$ & $5.7(1.7)$ & $0-7$ & $5.8(1.7)$ & $0-7$ \\
\hline DSB total & $5.2(2.2)$ & $0-9$ & $6.3(2.2)$ & $0-10$ & $5.0(2.3)$ & $0-9$ & $6.2(2.0)$ & $0-10$ \\
\hline coo total & $1.6(1.3)$ & $0-6$ & $1.6(1.3)$ & $0-6$ & $1.3(1.2)$ & $0-6$ & $1.6(1.3)$ & $0-6$ \\
\hline Total & $12.3(4.0)$ & $0-21$ & $13.6(4.2)$ & $0-21$ & $12.0(4.1)$ & $0-21$ & $13.5(4.1)$ & $0-21$ \\
\hline
\end{tabular}

K-TIS, Korean version of trunk impairment scale; SSB, Static sitting balance; DSB, Dynamic sitting balance; COO, Coordinatio. 
Table 3. Inter-rater and test-retest reliability for the K-TIS

$(N=51)$

\begin{tabular}{|c|c|c|c|c|c|c|}
\hline \multirow{2}{*}{ Inter-rater } & \multicolumn{3}{|c|}{ 1st test } & \multicolumn{3}{|c|}{ 2nd test } \\
\hline & $\mathrm{ICC}_{3,1}$ & $95 \% \mathrm{Cl}$ & $r$ & $\mathrm{ICC}_{3,1}$ & $95 \% \mathrm{Cl}$ & $r$ \\
\hline SSB total & 0.951 & $0.911-0.974$ & $0.958^{*}$ & 0.983 & $0.969-0.984$ & $0.984^{*}$ \\
\hline DSB total & 0.940 & $0.891-0.967$ & $0.940^{*}$ & 0.920 & $0.857-0.956$ & $0.924^{*}$ \\
\hline COO total & 0.925 & $0.892-0.948$ & $0.929^{*}$ & 0.939 & $0.889-0.966$ & $0.939 *$ \\
\hline Total & 0.938 & $0.922-0.969$ & $0.976^{*}$ & 0.961 & $0.929-0.979$ & $0.961^{*}$ \\
\hline \multirow{2}{*}{ Test-retest } & \multicolumn{3}{|c|}{ Rater A } & \multicolumn{3}{|c|}{ Rater B } \\
\hline & $\mathrm{ICC}_{3,1}$ & $95 \% \mathrm{Cl}$ & $r$ & $\mathrm{ICC}_{3,1}$ & $95 \% \mathrm{Cl}$ & $r$ \\
\hline SSB total & 0.896 & $0.815-0.943$ & $0.903^{*}$ & 0.901 & $0.824-0.949$ & $0.902^{*}$ \\
\hline DSB total & 0.875 & $0.670-0.839$ & $0.875^{*}$ & 0.873 & $0.667-0.810$ & $0.877^{*}$ \\
\hline COO total & 0.805 & $0.710-0.886$ & $0.809^{*}$ & 0.814 & $0.670-0.865$ & $0.806^{*}$ \\
\hline Total & 0.889 & $0.735-0.915$ & $0.879^{*}$ & 0.892 & $0.748-0.920$ & $0.895^{*}$ \\
\hline
\end{tabular}

${ }^{*} p<0.05$.

K-TIS, Korean version of trunk impairment scale; SSB, Static sitting balance; DSB, Dynamic sitting balance; COO, Coordination.

Table 4. Minimally important difference for the K-TIS

\begin{tabular}{|c|c|c|c|c|c|}
\hline & Baseline Mean \pm SD & After 1 mo. Mean \pm SD & Changes Mean \pm SD & $0.3 \times S_{b}$ & $0.5 \times S_{b}$ \\
\hline & \multicolumn{5}{|c|}{ Acute and post-acute stroke patients $(n=39)$} \\
\hline SSB total & $4.79 \pm 2.43$ & $6.26 \pm 1.37$ & $1.46 \pm 1.90^{*}$ & 0.73 & 1.22 \\
\hline DSB total & $3.62 \pm 2.81$ & $5.82 \pm 2.79$ & $2.36 \pm 1.97^{*}$ & 0.84 & 1.41 \\
\hline COO total & $1.56 \pm 1.45$ & $2.38 \pm 1.89$ & $0.82 \pm 1.19^{*}$ & 0.44 & 0.73 \\
\hline \multirow[t]{3}{*}{ Total } & $10.03 \pm 5.94$ & $14.46 \pm 5.29$ & $4.44 \pm 3.31$ * & 1.78 & 2.97 \\
\hline & Baseline Mean \pm SD & After 3 mo. Mean \pm SD & Changes Mean \pm SD & $0.3 \times S_{b}$ & $0.5 \times S_{b}$ \\
\hline & \multicolumn{5}{|c|}{ Chronic stroke patients $(n=12)$} \\
\hline SSB total & $6.08 \pm 0.29$ & $6.67 \pm 0.49$ & $0.58 \pm 0.51$ & 0.09 & 0.15 \\
\hline DSB total & $4.42 \pm 1.98$ & $6.25 \pm 1.60$ & $1.83 \pm 1.34$ & 0.59 & 0.99 \\
\hline COO total & $1.00 \pm 0.43$ & $1.25 \pm 0.62$ & $0.25 \pm 0.62$ & 0.13 & 0.22 \\
\hline Total & $11.50 \pm 2.35$ & $14.17 \pm 2.04$ & $2.67 \pm 1.30$ & 0.71 & 1.18 \\
\hline
\end{tabular}

${ }^{*} p<0.05$.

K-TIS, Korean version of trunk impairment scale; SSB, Static sitting balance; DSB, Dynamic sitting balance; COO, Coordination; Sb, Standard deviation of baseline.

\section{2. 한국판몸통손상척도의 민감도}

급성 및 급성기 이후 뇌졸중환자의 1 개월간의 집중 물리치료 후 민감 도는 정적앉기균형, 동적앉기균형, 협응력, 총점 등에서 각기 $\mathrm{MID}=0.73-1.22,0.84-1.41,0.44-0.73,1.78-2.97$ 로 $0.3 \times \mathrm{S}_{\mathrm{b}^{-}} 0.5 \times \mathrm{S}_{\mathrm{b}}$ 범위 내 에서 결과를 보여 민감도가 있는 것으로 나타났고, 3 개의 하위척도와 총점 모두 통계적으로도 유의한 것으로 나타났다 $(\mathrm{p}<0.05)$ (Table 4).

만성 뇌졸 중환자의 경우 동적앉기균형과 총점에서 민감도를 확인 할 수 있었지만 3 개월 전후의 점수변화는 통계적으로 유의하지 않았 다 $(\mathrm{p} \geq 0.05)$ (Table 4).

\section{고 찰}

본 연구는 뇌졸중 환자의 정적 및 동적 앉기에서 균형조절과 몸통의 선택적 조절능력을 평가도구인 TIS를 한글화하고, 한글화된 TIS의 신뢰도와 민감도를 조사해 K-TIS로 표준화하고자 하였다.
TIS의 한글화작업에서 문화적 차이에서 발생할 수 있는 오역을 없 애기 위하여 ${ }^{26}$ 원저자와 논의를 통해 엄격한 단어의 선별과정을 거쳤 다. 모국어가 아닌 외래어로 된 평가도구의 한글화 및 표준화 작업을 위하여 첫째, 해당 분야의 2 인 이상의 전문가에 의한 번역과 외래어 로의 재 번역이 필요하다. 재 번역된 내용을 바탕으로 원저자와의 논 의를 통하여 평가항목의 내용을 유지하면서 국내에서 이해하는데 가장 적합한 내용으로 전환하는 과정을 거쳐야 한다. 둘째, 평가도구 를 한글화 한 것으로 한국판평가도구가 개발되는 것이 아니므로, 실 제로 임상환자를 대상으로 신뢰도와 민감도를 조사해야 한다. ${ }^{27}$ 본 연구에서 조사한 측정자 간 신뢰도는 2 명 이상의 측정자가 동일한 측 정대상 1 명에게 같은 측정값을 부여하는 정도를 말하며, 검사-재검 사 신뢰도는 반복 측정한 값이 어느 정도 일치하는지 검사하는 것으 로 신뢰도 값이 ' 1 '일 경우 측정자 간에 그리고 반복 검사에서 측정값 이 완전히 일치한다는 뜻이다.

한글화한 TIS의 정적앉기균형, 동적앉기균형, 그리고 협응력 등의 
3 개 하위 영역의 측정자 간 신뢰도는 급내상관계수 ICC와 피어슨상 관계수 r에서 모두 0.9 이상의 높은 신뢰도를 나타냈다. 이 결과는 Verheyden 등16이 TIS를 개발할 때 발병일 21일에서 2,341일의 범위를 갖 는 28 명의 뇌졸중 환자를 대상으로 조사한 측정자 간 신뢰도 ICC $=0.87-0.96$ 과 유사하다. 검사-재검사 신뢰도의 경우, 측정자 $\mathrm{A}$ 와 $\mathrm{B}$ 의 신뢰도 값이 ICC $=0.805-0.896, \mathrm{ICC}=0.814-0.901$ 로 Verheyden 등'의 결과와약간 낮거나 유사하다.

본 연구의 측정자 간 신뢰도값과 검사-재검사신뢰도 값을 비교했 을 때 측정자간 신뢰도 값이 검사-재검사 신뢰도 보다 높게 나타났다. 이와 같은 결과가 나타난 것은 측정자 간 신뢰도의 경우 2 명의 측정 자가 같은 시간에 동일한 비디오를 보면서 점수를 측정하기 때문에 영향을 미칠 수 있는 여러 요인들의 작용이 최소화된다. 하지만, 검 사-재검사 신뢰도에서는 환자의 수행능력 내에서 변이가 작용했을 수 있다. 특히, 본 연구의 대상자의 경우 뇌졸중 발병기간이 3 개월 미 만인 급성 및 급성기 이후 환자가 $76 \%$ 이상이기 때문에 2 주 간격의 검 사-재검사 기간 사이에 앉기 균형 및 몸통조절력에 변화가 생길 수도 있었을 것으로 생각된다. 뇌졸중 발병 3 개월 미만의 환자의 K-TIS의 검사-재검사신뢰도를 조사할 경우 검사 간 시기를 2 주 이내로 보다 짧게 시간 간격을 둘 필요가 있을 것으로 생각된다.

민감도란, 시간의 경과 또는 치료 전· 후에 임상적으로 중요한 변화 가 있을 때 측정한 점수변화로 실제적 기능적 변화를 설명할 수 있는 평가도구의 특성을 뜻한다. ${ }^{2}$ 물리치료분야에서 표준화 또는 객관화 된 평가도구라고 한다면 치료의 결과를 숫자화 된 데이터로 제공하 여 물리치료의 효과를 잘 입증해 줄 수 있어야 한다. TIS의 경우 아직 치료 및 시간의 경과에 따른 민감도가 발표된 연구는 없다. 본 연구에 서는 국내의 뇌졸중 환자 치료 및 입원기간 등의 여건을 고려하여 발 병기간 3 개월 미만의 환자들은 1 개월의 입원기간 동안 그리고 6 개월 이상 된 환자들은 3 개월의 입원기간 동안 집중운동치료 전후의 K-TIS의 점수변화를 이용하여 민감도를 측정하였다.

Table 4 에서 발병기간 3 개월 미만의 뇌졸중 환자의 경우 1 개월 간 의 정적앉기균형에서의 점수변화는 4.79점에서 6.26점으로 1.46 점 증 가하였다. 그리고 Table 4 에서 제시하고 있는 $0.3 \times \mathrm{S}_{\mathrm{b}}=0.73$ 과 $0.5 \times$ $S_{b}=1.22$ 의 의미는 1 개월간의 치료 후에 점수변화가 $0.73-1.22$ 점의 점 수 범위에 해당되거나 또는 1.22점 보다 클 경우 정적앉기균형에서 의 미 있는 변화가 일어난 것으로 해석한다. 동적앉기균형과 협응력에서 도 각기 1.41 점과 0.73 점 보다 큰 점수변화를 나타내어 발병 3 개월 미 만의 뇌졸중 환자에게 1 개월 간의 집중치료가 효과적이었다고 할 수 있다. Harley와 Fragara-Pinkham ${ }^{29}$ 은 치료 전후의 평가점수의 변화량 이 $0.3 \times \mathrm{S}_{\mathrm{b}}$ 값과 $0.5 \times \mathrm{S}_{\mathrm{b}}$ 값의 점수 범위에 포함될 때 해당 평가도구의 민감도가 높다고 하였다.

발병 6 개월 이상의 뇌졸중 환자의 경우, K-TIS의 3 개 하위영역에서
모두 민감도를 확인할 수 있었다. 하지만, 정적앉기균형, 동적앉기균 형, 협응력에서의 점수변화가 3 개월간의 집중치료 후에도 발병 3 개월 미만의 급성 및 급성기 이후 뇌졸중 환자에 비해 낮게 나타났다. 문헌 보고에 의하면, 뇌졸중 발병 후 뇌의 가소성 및 물리치료를 통한 기능 의 회복은 발병 후 3 개월 내에 가장 극대화 된다고 한다. ${ }^{30}$ 본 연구의 결과도 이러한 내용을 뒷받침하고 있다. 뇌졸중 환자에게 K-TIS를 적 용할 때는 뇌졸중 발병 시기에 따른 운동회복 능력을 고려하여 만성 뇌졸중 환자라면 3 개월 이상의 운동기간을 계획하는 것이 K-TIS를 이용한 물리치료의 효과를 확인하는데 적합할 것으로 생각한다.

본 연구의 제한점으로는 만성뇌졸중 환자의 수가 비교적 적었다 는 것과 2 개 기관의 환자들을 대상으로 하였기 때문에 연구의 결과 를 일반화 하기 어렵다는 것이다. 향후 K-TIS를 이용한 연구가 이루어 진다면 첫째, 다수의 기관이 참여하는 큰 규모의 환자를 대상으로 신 뢰도와 민감도 조사가 이루어져야 할 것이며, K-TIS를 사용하는 기관 별로 신뢰도와 민감도를 조사하는 것도 보다 실제적인 방법이 될 것 이다. 둘째, 다양한 뇌졸중 환자 물리치료 중재법에 대한 K-TIS의 민 감도를 조사하여 중재법에 따른 K-TIS의 적용을 확인 후 환자사례 및 치료접근법에 따른 적용을 연구해야 할 것이다. 마지막으로, K-TIS 의 17 개 항목은 일상생활에서 주로 취하는 기능적 자세와 움직임으 로 구성되어 있다. 예를 들어서 K-TIS의 협응력 부분에는 무릎을 앞 으로 6회 움직이는 항목이 있고 6초 안에 수행해야 한다. 이 항목들 에서는 일상생활에서 다리의 움직임이 포함되는 대부분의 기능적 동작에 필수적인 하부몸통의 선택적 회전동작을 평가하는 것이며 정상인처럼 적절한 시간 안에 수행하는지 평가하는 것이다. 때문에 뇌졸중 환자의 물리치료의 목표와 치료프로그램을 계획할 때 TIS의 17 개 항목을 이용하여 개개인의 환자에게 적합한 항목이나 항목들 을 단기적 치료목표로 설정해 치료시간에 집중적으로 반복 연습시 킨다면 기능적 회복에 도움이 될 수 있을 것이다.

본 연구의 결과를 종합해 볼 때, K-TIS는 신뢰도와 시간의 경과에 따른 민감도를 갖춘 임상과 연구의 목적으로 뇌졸중 환자의 앉은 자 세에서 균형조절과 몸통조절력을 평가할 수 있는 유용한 평가도구 라고 생각된다.

\section{REFERENCES}

1. Sacco RL, Kasner SE, Broderick JP et al. An updated definition of stroke for the 21st century: a statement for healthcare professionals from the American Heart Association/American Stroke Association. Stroke. 2013;44(7):2064-89.

2. National Statistical Office. Annual report on the cause of death statistics. 2009.

3. Meijer R, Ihnenfeldt DS, de Groot IJ et al. Prognostic factors for ambulation and activities of daily living in the subacute phase after stroke. A sys- 
tematic review of literature. Clin Rehabil. 2003;17(2):119-29.

4. Meijer R, Ihnenfeldt DS, van Limbeek J et al. Prognostic factors in the subacute phase after six months to one year. A systematic review of literature. Clin Rehabil. 2003;17(5):512-20.

5. Winzeler-Mercay U, Mudie H. The nature of the effects of stroke on trunk flexor and extensor muscles during work and at rest. Disabil Rehabil. 2002;24(17):875-86.

6. Karatas M, Cetin N, Bayramoglu M et al. Trunk muscle strength in relation to balance and functional disability in unihemispheric stroke patients. Am J Phys Med Rehabil. 2004;83(2):81-7.

7. Verheyden G, Nieuwboer A, De wit L et al. Trunk performance after stroke: an eye catching predictor of functional outcome. J Neurol Neurosurg Psychiatry. 2007;78(7):694-98.

8. Yang DJ, Park SK, Kang JI et al. Effects of changes in postural alignment on foot pressure and balance of patients with stroke. J Kor Phys Ther. 2014;26(4):226-33.

9. Monaco MD, Trocco M, Monarco RD et al. The relationship between initial trunk control or postural balance and inpatient rehabilitation outcome after stroke: a prospective comparative study. Clin Rehabil. 2010; 24(6):543-54.

10. Verheyden G, Nieuwboer A, De wit L et al. Time course of trunk, arm, leg, and functional recovery after ischemic stroke. Neurorehabil Neural Repair. 2008;22(2):173-9.

11. World Health Organization. International classification of functioning, disability and health. ICF. Geneva: World Health Organization. 2001.

12. Nieuwboer A, Feys H, De Weedt W et al. Developing a clinical tool to measure sitting balance after stroke: a reliability study. Physiotherapy. 1995;81(8):439-45.

13. Collin C, Wade D. Assessing motor impairment after stroke: a pilot reliability study. J Neurol Neurosurg Psychiatry. 1990;53(7):576-79.

14. Lincoln N, Leadbitter D. Assessment of motor function in stroke patients. Physiotherapy. 1979;65(2):48-51.

15. Gowland CA. Staging motor impairment after stroke. Stroke. 1990;21(9 Suppl):II 19-21.

16. Verheyden G, Nieuwboer A, Mertin J et al. The trunk impairment scale: a new tool to measure motor impairment of the trunk after stroke. Clin Rehabil. 2004;18(3):326-34.
17. Tyson SF, Connell LA. How to measure balance in clinical practice. A systematic review of the psychometrics and clinical utility of measure of balance activity for neurological conditions. Clin Rehabil. 2009;23(9): 824-40.

18. Kim TJ, Seo KM, Kim DK et al. The relationship between initial trunk performances and functional prognosis in patients with stroke. Ann Rehabil Med. 2015;39(1):66-73.

19. Verheyden G, Kersten P. Investigating the internal validity of the trunk impairment scale using rasch analysis: the TIS 2.0 Disability and Rehabiliation. 2010;32(25):2127-37.

20. Jeong DH. Reliability and Validity of the CAP for Computer Access Assessment of Persons with Physical Disabilities. J Kor Phys Ther. 2015; 27(1):30-7.

21. Kim DY, Choi JD, Ki KI. A reliability study of sit-to-walk for dynamic balance assessment in stroke patient. J Kor Phys Ther. 2013;25(5):303-10.

22. Chang WN, Lee KB, Yeom JW et al. Analysis of Intrarater and Interrater Reliability of Trunk Repositioning Error Test using a Portable Digital Inclinometer. J Kor Phys Ther. 2013;25(4):210-6.

23. Lee IH. Reliability of Visual Gait Analysis according to Clinical Experience Level of Physical Therapists. J Kor Phys Ther. 2013;25(4):174-9.

24. Watkins MO, Portney LG. Foundations of clinical research: applications to practice. East Norwalk: Conn Appleton and Lange. 1993:53-67.

25. Adair B, Said CM, Rodda J et al. Psychometric properties of functional mobility tools in hereditary spastic paraplegia and other childhood neurological conditions. Dev Med Child Neurol. 2012;54(7):596-605.

26. Yoo SH, Ha HK, Lee HJ. Korean Cultural Adaptation of Working Alliance Inventory and Its Reliability. J Kor Phys Ther. 2014;26(2):90-6.

27. Kim HS, Her JG, Ko JY et al. Reliability, concurrent validity, and responsiveness of the Fugl-Meyer assessment (FMA) for hemiplegic patients. J Phys Ther. Sci. 2012;24(9):893-9.

28. Giraudeau B, Ravaud P, Chastang C. Importance of reproducibility in responsiveness issues. Biometrical J. 1998;40(6):685-701.

29. Harley SM, Fragara-Pinkham MA. Interpreting change scores of tests and measures used in Physical Therapy. Phys Ther. 2006;86(5):735-43.

30. Langhorne P, Coupar F, Pollock A. Motor recovery after stroke: a systematic review. Lancet Neurol. 2009;8(8):741-54. 


\section{Appendix 1.}

\section{Korean version of Trunk Impairment Scale (K-TIS)}

항목마다 시작 자세는 동일하다. 환자는 침대 또는 치료 테이블 가장자리에 기대거나 손을 짚지 않고 앉는다. 허벅지는 침대나 테이 블에 완전히 닿아야 하고, 발은 엉덩이 너비만큼 벌려 바닥에 편평하게 닿게 한다. 무릎은 $90^{\circ}$ 굴곡시킨다. 양 팔은 다리 위에 올려 놓는다. 평가 중 마비측 팔에 긴장도가 높아지면 다시 시작자세로 취하게 한다. 머리와 몸통은 가운데로 정렬 시킨다.

환자가 첫 항목에서 0 점이면 ‘TIS 총점’은 0 점이다.

항목마다 3 회 수행시킨 후 가장 높은 점수를 선택한다. 환자가 평가항목을 별도로 연습하지 않도록 한다. 치료사는 환자가 항목을 수행할 때 '구두(verbal)'로 피드백을 줄수 있다.

말로 항목수행에 관해 설명하거나 필요하다면 직접 시범을 보여주어도 된다. 
Korean version of Trunk Impairment Scale (K-TIS)

\begin{tabular}{|c|c|c|c|}
\hline 항목 & & & \\
\hline \multirow[t]{2}{*}{1} & \multirow[t]{2}{*}{$\begin{array}{l}\text { Static sitting balance } \\
\text { 시작자세 }\end{array}$} & $\begin{array}{l}\text { · 환자가 팔로 지지하지 않으면 넘어지거나 10초 동안 시작자세를 유지하지 못 한다. } \\
\text { - } 10 \text { 초 동안 시작자세를 유지한다. }\end{array}$ & \multirow[t]{2}{*}{$\begin{array}{l}\square 0 \\
\square 2\end{array}$} \\
\hline & & '엄'인 경우 TIS의 총점은 '0점' & \\
\hline 2 & $\begin{array}{l}\text { 시작자세에서 치료사가 비마비측 다리를 마비측 다리 } \\
\text { 위로 교차시킨다. }\end{array}$ & $\begin{array}{l}\text { · 환자가 팔로 지지하지 않으면 넘어지거나 } 10 \text { 초 동안 시작자세를 유지하지 못 한다. } \\
\text { ·자가 앉은 자세를 } 10 \text { 초 동안 유지한다. }\end{array}$ & $\begin{array}{l}\square 0 \\
\square 2\end{array}$ \\
\hline 3 & $\begin{array}{l}\text { 시작자세에서 환자가 비마측 다리를 마비측 다리 위 } \\
\text { 로 교차시킨다. }\end{array}$ & $\begin{array}{l}\text { · 환자가 넘어진다. } \\
\text { • 환자가 침대나테에블에 팔의 지지 없이 다리를 교차시키지 못 한다. } \\
\text { · 환자가 다리를 교차시키지만 몸통이 } 10 \mathrm{~cm} \text { 이상 뒤로 기울어지거나 손으로 다리를 넘긴다. } \\
\text { • 환자가 몸통을 뒤로 기울이거나 손을 쓰지 않고 다리를 교차시킨다. } \\
\text { Total static sitting balance }\end{array}$ & $\begin{array}{r}\square 0 \\
\square 1 \\
\square 2 \\
\square 3 \\
17\end{array}$ \\
\hline 1 & $\begin{array}{l}\text { Dynamic sitting balance } \\
\text { 시작자세에서 환자에게 마비측 팔꿈치가 침대나 테이 } \\
\text { 블에 닿게(마비측 체간은 짧게 하고 비마비측은 길게 } \\
\text { 함으로서) 한 후 시작자세로 돌아오게 한다. }\end{array}$ & $\begin{array}{l}\text { ·환자가 넘어지거나, 상지로 기대거나, 팔꿈치가 침대나 테이블에 닿지 않는다. } \\
\text { • 환자가 도움 없이 능동적으로 움직이고, 팔꿈치가 침대나 테이블에 닿는다. } \\
\text { '점'인 경우 2번 및 3번 항목도 '0점'처리한다 }\end{array}$ & $\begin{array}{l}\square 0 \\
\square 1\end{array}$ \\
\hline \multirow[t]{2}{*}{2} & \multirow[t]{2}{*}{ 1번 항목을 반복한다. } & $\begin{array}{l}\text { - 환자가 치료사의 지시대로 수행하지 못하거나 마비측 체간이 길어지고 비마비측이 짧아 진다. } \\
\cdot \text { 환자가 적절히 마비측 체간을 짧게 하고 비마비측은 길게 한다. }\end{array}$ & \multirow[t]{2}{*}{$\begin{array}{l}\square 0 \\
\square 1\end{array}$} \\
\hline & & '0점'인 경우 3번 항목도 '0점'처리한다 & \\
\hline 3 & 1번 항목을 반복한다. & $\begin{array}{l}\text { - 환자가 다음과 같은 보상작용을 한다: (1) 상지의 사용, (2) 반대쪽 고관절 외전, } \\
\text { (3) 고관절 굴곡(팔꿈치가 대퇴골 근위부 1/2을 지나서 테이블이나 침대에 닿는 경우), } \\
\text { (4) 슬관절 굴곡, (5) 발의 미끄러짐 } \\
\text { - 환자가 보상작용 없이 움직인다. }\end{array}$ & $\begin{array}{l}\square 0 \\
\square 1\end{array}$ \\
\hline \multirow[t]{2}{*}{4} & \multirow{2}{*}{$\begin{array}{l}\text { 시작자세에서 환자에게 비마비측 팔꿈치가 침대나 테 } \\
\text { 이블에 닿게(비마비측 체간을 짧게 하고 마비측은 길 } \\
\text { 게 함으로서) 한 후 시작자세로 돌아오게 한다. }\end{array}$} & $\begin{array}{l}\text { · 환자가 넘어지거나, 상지로 기대거나, 팔꿈치가 침대나 테이블에 닿지 않는다. } \\
\text { · 환자가 도움 없이 능동적으로 움직이고, 팔꿈치가 침대나 테이블에 닿는다. }\end{array}$ & \multirow[t]{2}{*}{$\begin{array}{l}\square 0 \\
\square 1\end{array}$} \\
\hline & & '0점'인 경우 5번 및 6번 항목도 '0점'처리한다 & \\
\hline \multirow[t]{2}{*}{5} & \multirow[t]{2}{*}{ 4번 항목을 반복한다. } & $\begin{array}{l}\text { - 환자가 치료사의 지시대로 수행하지 못하거나 마비측 체간이 짧아지고 비마비측이 길어진다. } \\
\text { - 환자가 적절히 비마비측 체간을 짧게 하고 마비측은 길게 한다. }\end{array}$ & \multirow[t]{2}{*}{$\begin{array}{l}\square 0 \\
\square 1\end{array}$} \\
\hline & & '0점'인 경우 6번 향목도 'O점'처리한다 & \\
\hline 6 & 4번 항목을 반복한다. & $\begin{array}{l}\text { - 환자가 다음과 같은 보상작용을 한다: (1) 상지의 사용, (2) 반대쪽 고관절 외전, } \\
\text { (3) 고관절 굴곡(팔꿈치가 대퇴골 근위부 } 1 / 2 \text { 을 지나서 테이블이나 침대에 닿는 경우), } \\
\text { (4) 슬관절 굴곡, (5) 발의 미끄러짐 } \\
\text { - 환자가 보상작용 없이 움직인다. }\end{array}$ & $\begin{array}{l}\square 0 \\
\square 1\end{array}$ \\
\hline \multirow[t]{2}{*}{7} & \multirow{2}{*}{$\begin{array}{l}\text { 시작자세에서 환자에게 침대나 테이블에서 마비측 골 } \\
\text { 반을 들어올리고(마비측 체간은 짧게 하고 비마비측 } \\
\text { 을 길게 함으로서) 다시 시착자세로 돌아온다. }\end{array}$} & $\begin{array}{l}\text { - 환자가 치료사의 지시대로 수행하지 못하거나 마비측 체간이 길어지고 비마비측이 짧아 진다. } \\
\text { · 환자가 적절히 마비측 체간을 짧게 하고 비마비측은 길게 한다. }\end{array}$ & \multirow[t]{2}{*}{$\begin{array}{l}\square 0 \\
\square 1\end{array}$} \\
\hline & & '0점'인 경우 8번 항목도 '0점’ 처리한다. & \\
\hline 8 & 7번 항목을 반복한다. & $\begin{array}{l}\text { · 환자가 다음과 같은 보상작용을 한다: (1) 상지의 사용, (2) 마비측 발꿈치 들기 } \\
\text { (push off: 발뒤꿈치가 바닥에서 떨어진다) } \\
\text { • 환자가 보상작용 없이 움직인다. }\end{array}$ & $\begin{array}{l}\square 0 \\
\square 1\end{array}$ \\
\hline \multirow[t]{2}{*}{9} & \multirow{2}{*}{$\begin{array}{l}\text { 시작자세에서 환자에게 침대나 테이블에서 비마비측 } \\
\text { 골반을 들어올리고(비마비측 체간은 짧게 하고 마비 } \\
\text { 측을 길게 함으로서) 다시 시작자세로 돌아온다. }\end{array}$} & $\begin{array}{l}\text { · 환자가 치료사의 지시대로 수행하지 못하거나 비마비측 체간이 길어지고 마비측이 짧아 진다. } \\
\text { · 환자가 적절히 비마비측 체간을 짧게 하고 마비측은 길게 한다. }\end{array}$ & \multirow[t]{2}{*}{$\begin{array}{l}\square 0 \\
\square 1\end{array}$} \\
\hline & & “점인 경우 10번 항목도 'O점’처리한다 & \\
\hline \multirow[t]{2}{*}{10} & \multirow[t]{2}{*}{ 9번 항목을 반복한다. } & $\begin{array}{l}\text { - 환자가 다음과 같은 보상작용을 한다: (1) 상지의 사용, (2) 비마비측 발뒤꿈치 들기 } \\
\text { (push off: 발뒤꿈치가 바닥에서 떨어진다) } \\
\text { • 환자가 보상작용 없이 움직인다. }\end{array}$ & $\begin{array}{l}\square 0 \\
\square 1\end{array}$ \\
\hline & & Total dynamic sitting balance & $/ 10$ \\
\hline \multirow[t]{2}{*}{1} & \multirow{2}{*}{$\begin{array}{l}\text { Co-ordination } \\
\text { 시작자세에서 환자에게 상부체간을 } 6 \text { 회 회전시키는 } \\
\text { 데(양쪽 어깨가 앞으로 } 3 \text { 회 움직여야 함), 마비측부터 } \\
\text { 움직여야 하고 머리는 시작자세로 유지해야 한다. }\end{array}$} & $\begin{array}{l}\text { • 마비측이 3회 움직이지 않는다. } \\
\text { • 회전이 비대칭적으로 일어난다. } \\
\text { • 회전이 대칭적으로 일어난다. }\end{array}$ & \multirow[t]{2}{*}{$\begin{array}{l}\square 0 \\
\square 1 \\
\square 2\end{array}$} \\
\hline & & '0점'인 경우 2번 항목도 'O점'처리한다 & \\
\hline 2 & 6초 내에 1번 항목을 반복한다. & $\begin{array}{l}\text { ·회전이 비대칭적으로 일어난다. } \\
\text { ·회전이 대칭적으로 일어난다. }\end{array}$ & $\begin{array}{l}\square 0 \\
\square 1\end{array}$ \\
\hline \multirow[t]{2}{*}{3} & \multirow{2}{*}{$\begin{array}{l}\text { 시작자세에서 환자에게 하부 체간을 } 6 \text { 회 회전시키는 } \\
\text { 데(양쪽 무릎이 앞으로 } 3 \text { 회 움직여야 함), 마비측부터 } \\
\text { 움직여야 하고, 상부 체간은 시작자세로 유지해야 한 } \\
\text { 다. }\end{array}$} & $\begin{array}{l}\text { • 마비측이 3회 움직이지 않는다. } \\
\text { • 회전이 비대칭적으로 일어난다. } \\
\text { • 회전이 대칭적으로 일어난다. }\end{array}$ & \multirow[t]{2}{*}{$\begin{array}{l}\square 0 \\
\square 1 \\
\square 2\end{array}$} \\
\hline & & 'O'점인 경우 4번 항목도 'O점' 처리한다 & \\
\hline \multirow[t]{3}{*}{4} & \multirow[t]{3}{*}{ 6초 내에 1번 항목을 반복한다. } & $\begin{array}{l}\text { • 회전이 비대칭적으로 일어난다. } \\
\text { ·회전이 대칭적으로 일어난다. }\end{array}$ & $\begin{array}{l}\square 0 \\
\square 1\end{array}$ \\
\hline & & Total co-ordination & 16 \\
\hline & & Total Trunk Impairment Scale & 123 \\
\hline
\end{tabular}

